\title{
Asthma in South African adolescents: a time trend and risk factor analysis over two decades
}

Cynthia B. Baard, Zoe Franckling-Smith, Jacinta Munro, Lesley Workman and Heather J. Zar

Affiliation: University of Cape Town, Dept of Paediatrics and Child Health, Red Cross War Memorial Children's Hospital, and the SA-MRC Unit on Child and Adolescent Health, University of Cape Town, Cape Town, South Africa.

Correspondence: Heather J. Zar, Room 513, ICH Building, Red Cross Children's Hospital, Klipfontein Road, Rondebosch 7700, South Africa. E-mail: heather.zarduct.ac.za

\section{ABSTRACT}

Background: South Africa has undergone major economic and health system changes, impacting the epidemiology of childhood asthma. This study aimed to investigate prevalence time trends of asthma in South African adolescents over two decades and to identify associated risk factors.

Methods: A cross-sectional survey was conducted in 2017, in a randomised sample of 13-14-year-old Cape Town adolescents, using the standardised Global Asthma Network written, video and environmental questionnaires. Using time-trend analysis, the prevalence and severity of asthma were compared with data from the 2002 ISAAC phase III study. Environmental and social risk factors were analysed.

Results: A total of 3979 adolescents were included. The prevalence of lifetime and current asthma were $34.5 \%$ and $21.3 \%$, respectively, on the self-report written questionnaire, similar to 2002 results. The prevalence of severe asthma in the previous 12 months increased, measured by wheeze limiting speech (7.8\% to $11.8 \%)$, four or more attacks of wheezing $(5.0 \%$ to $5.8 \%)$ or woken by wheeze on one or more nights per week (5.0\% to $6.9 \%)$. The video questionnaire revealed increases in lifetime (16.9\% to $22.5 \%$ ), current $(11.2 \%$ to $18.7 \%)$ and severe asthma (12.1\% to $14.8 \%)$. Multivariate analysis showed associations between current asthma and smoking, female sex, pet exposure and higher socioeconomic status. Severe asthma was associated with smoking, pet exposure, outdoor pollution exposure and informal housing; 33\% of those with severe or current asthma had been diagnosed.

Conclusion: The prevalence of asthma is high, with increasing rates of severe asthma in adolescents. Underdiagnosis is a major concern and reduction in exposure to environmental factors, particularly smoking, and improved socioeconomic development are needed.

@ERSpublications

Among South African adolescents, the prevalence of asthma is high, with increasing rates of severe asthma from 1995 to 2017. Smoking, poor living conditions and exposure to pets or air pollution are risk factors. Underdiagnosis is a major concern. https://bit.ly/3171DKy

Cite this article as: Baard CB, Franckling-Smith Z, Munro J, et al. Asthma in South African adolescents: a time trend and risk factor analysis over two decades. ERJ Open Res 2021; 7: 005762020 [https://doi.org/10.1183/23120541.00576-2020].

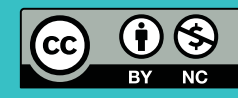

\section{Received: 13 Aug 2020 | Accepted: 2 Nov 2020}

Copyright $\odot$ ERS 2021. This article is open access and distributed under the terms of the Creative Commons Attribution Non-Commercial Licence 4.0. 


\section{Introduction}

Asthma is the most common chronic disease in children, and a major contributor to childhood morbidity [1-3], impacting on physical, psychological and social aspects of life [4]. Accumulating data have shown an increasing prevalence of childhood asthma in low to middle income countries (LMICs) in both urban and rural areas $[2,5,6]$. In addition, disease severity has been found to be higher in children living in LMICs than in high-income populations [7]. Resource constraints, resulting in inadequate diagnosis and follow-up of childhood asthma, as well as lack of availability of essential asthma drugs in the setting of rapid urbanisation, environmental changes, poverty and sub-standard living conditions, are challenges frequently faced by populations in LMICs, potentially contributing to this burden of disease [8].

The International Study of Asthma and Allergies in Childhood (ISAAC) has provided the most comprehensive data on the epidemiology of childhood asthma and changes over time [9]. Data from Cape Town showed a substantial increase in asthma prevalence in adolescents as measured by self-reported current wheeze, from $16.0 \%$ in 1995 (ISAAC I) to $20.3 \%$ in 2002 (ISAAC III) [9], which was higher than the global prevalence of $14.1 \%$ [3]. The proportion diagnosed with asthma during these periods was $13.3 \%$ and $14.4 \%$, respectively. Underdiagnosis of childhood asthma was commonly reported in ISAAC III in LMICs, with as many as $50 \%$ of cases of asthma being undiagnosed [3]. Further, the prevalence of severe asthma was much higher in LMICs, with up to $30 \%$ of children with asthma reporting severe symptoms. Consistent with this, data from Cape Town showed that amongst children with asthma symptoms, approximately half had symptoms of severe, uncontrolled asthma $[9,10]$.

Since 2002, South Africa has experienced profound changes in society and policies, with strengthening of healthcare provision, rapid urbanisation and improved access to basic amenities such as water, sanitation and electricity as well as basic education $[11,12]$. However, challenges such as poverty, unemployment, socioeconomic inequity and sub-optimal health systems have continued to negatively impact on health $[11,13]$. The aim of this study was to investigate time trends in the prevalence of asthma in South African adolescents from 2002 to 2017, and to identify risk factors associated with asthma or asthma severity.

\section{Methods}

Study design

A cross-sectional survey of 13- and 14-year-old school-going adolescents in Cape Town, South Africa, using the standardised written and video questionnaires developed by the Global Asthma Network (GAN; a follow-on study to ISAAC), and an environmental questionnaire, was conducted from 1 June to 31 October 2017. These results were compared to those from the ISAAC phase III study (2002) done in the same area of Cape Town over the same season, to identify changes in asthma prevalence or severity and associated risk factors.

\section{Population}

Public and private schools with learners aged 13 and 14 years within the Cape Town metropolitan area were randomised and consecutively selected until the required sample size was achieved. Schools varied by language of instruction (English, isiXhosa and Afrikaans). Inclusion criteria for participants were: all pupils from selected schools who were aged 13-14 years during the data collection period with a signed consent form. Each school was visited two or three times to ensure data from eligible children that could not be surveyed at the first visit were captured.

\section{Methods}

Questionnaires were self-administered in the language preference of each learner, according to a standardised manual developed by GAN [14]. The questionnaires were translated from English into isiXhosa and Afrikaans, and were validated through back-translation. The environmental questionnaire was adapted for local use; this environmental questionnaire was developed by the ISAAC Steering Committee and previously used by our group in ISAAC III. It included questions about diet, height, weight, heating and cooking fuels, exercise, pets, family size, tobacco smoke and pollution exposure, and socioeconomic status (SES) including variables previously validated such as parental employment, home type and number of household items [6]. As with ISAAC, the written questionnaire was completed first, followed by the environmental questionnaire and then the video questionnaire. The current questionnaires were administered during the same season (autumn and winter) as ISAAC III, to control for seasonality. Following completion of the questionnaires, the weight and height of each child were measured by trained study staff using the Charder Medical Portable Digital Scale (HEBEI, Charder Electronic Co., Inc., Taiwan) and the Charder Portable Stadiometer (HM200P, Charder Electronic Co., Inc., Taiwan).

The study was approved by the Human Research Ethics Committee of the Faculty of Health Sciences, University of Cape Town, South Africa. An opt-out method of consent was used for parents. Consent was 
obtained from each participant. Approval was obtained from the Department of Education, Western Cape, and from the principal of each participating school.

\section{Statistical analysis}

The study aimed to enrol 3500 participants, as this sample size was required to detect yearly changes of at least $0.5 \%$ in the prevalence of asthma compared to ISAAC III with a power of $90 \%$ and $95 \%$ confidence.

As per GAN methodology [14], each response was treated independently, and lifetime asthma was defined as a positive response to ever having wheezing or whistling in the chest, whereas current asthma was defined by having experienced wheezing in the past 12 months on the written questionnaires [14]. On the video questionnaire, lifetime or current asthma (within last 12 months) were defined as a positive response to experiencing symptoms depicted on any of the first four video sequences.

Severe asthma was defined according to GAN and ISAAC [14] as a positive response to one of the following in the past 12 months on the written questionnaire: 1) four or more attacks of wheezing; 2) woken by wheeze on one or more nights per week; 3) wheezing severe enough to limit speech to only one or two words at a time, between breaths. Severe asthma on the video questionnaire was defined as a positive response to a person at rest experiencing wheeze limiting speech (Scene Five) as per GAN guidelines [14].

Outdoor pollution was measured by responses to a frequency question related to trucks passing by the respondent's home. Responses of "frequently", or "almost the whole day" were classified as being exposed to outdoor pollution [14].

SES was assessed using a list of 10 common household items, adapted from an SES scoring system used in the South African Stress and Health study [15]. The median number of assets reported by the surveyed population was six assets and a cut-point was established. Lower SES was defined as a household with six or fewer assets and higher SES defined as a household with seven or more assets.

\section{TABLE 1 Participant characteristics}

\begin{tabular}{lc} 
Category & Total $\mathbf{n}=\mathbf{3 9 7 9}$ \\
\hline Male & $1731(43.5)$ \\
Ancestry & \\
$\quad$ Black African & $1699(42.7)$ \\
Caucasian & $463(11.6)$ \\
Mixed ancestry & $1683(42.3)$ \\
Other & $134(3.4)$ \\
School type & $3771(94.8)$ \\
Public & $208(5.2)$ \\
Private & \\
Highest level of maternal education & $298(7.5)$ \\
Primary school & $2002(50.3)$ \\
Secondary & $1597(40.1)$ \\
Tertiary & $82(2.1)$ \\
Not reported & $279(7.0)$ \\
Previous tuberculosis treatment & $1334(33.5)$ \\
Outdoor pollution & $348(8.8)$ \\
Self-reported smoking (current) & $982(24.7)$ \\
Maternal smoking & $1402(35.2)$ \\
Paternal smoking & $288(7.2)$ \\
Wood used for heating or cooking & $2711(68.1)$ \\
Exposure to pets & $3523(88.5)$ \\
Mother or father employed & $417(10.5)$ \\
Home type - informal home & $1975(49.6)$ \\
Household assets $(<7$ items) & \\
Body mass index kg-m ${ }^{-2}$ & $1105(27.8)$ \\
Less than 18.5 & $2119(53.2)$ \\
18.5 to 24.99 & $747(18.8)$ \\
Above 25 & $8(0.2)$ \\
Not reported &
\end{tabular}


Data were entered using REDCap (Research Electronic Data Capture) electronic data capture tools. As part of the data quality control process, a random $10 \%$ sample was used for independent double data entry. The original database containing all entries and the sample were compared using STATA version 14.2 (College Station, Texas, USA). The process resulted in an error rate of $0.3 \%$, within the standard allowance for acceptable error.

The data for this study were analysed using STATA version 13.0 (College Station, Texas, USA). Differences in disease prevalence were investigated using logistic regression, odds ratios and $95 \%$ confidence intervals. Risk factors were identified through univariate and multivariate logistic regression. Results were compared to those from the ISAAC III study to reveal time trends over the period.

\section{Results}

There were 4234 participants, of whom 3979 (94\%) met the age eligibility criteria. Of these, 1731 (43.5\%) were male (table 1); the demographic profile of the sample was representative of the current official population profile of Cape Town [16]. Environmental exposures that were highly prevalent included outdoor pollution (33.5\%), maternal smoking (24.7\%), paternal smoking (35.2\%), and participant self-reported current smoking (8.8\%). Exposure to pets was common, occurring in 68.1\% (table 1). Measures of lower SES included living in an informal dwelling (10.5\%) and having fewer than seven household assets (49.6\%) (table 1). Most participants (94.8\%) attended public schools, as occurs in South Africa; those attending private schools are largely adolescents from higher SES populations. On measurement of anthropometry, $18.8 \%$ of participants were obese, as defined by a body mass index (BMI) $>25$ (table 1).

\section{Prevalence of symptoms of asthma by self-reported questionnaire}

The prevalence of self-reported lifetime $(34.5 \%)$ or current asthma $(21.3 \%)$ did not increase significantly from ISAAC III (table 2). However, the prevalence of severe asthma as measured by night waking due to wheezing increased significantly, from $5.0 \%$ to $6.9 \%(\mathrm{OR}=1.41(1.18-1.68))$, wheeze limiting speech increasing from $7.8 \%$ to $11.8 \%(\mathrm{OR}=1.57(1.36-1.80))$ and four or more attacks of wheezing in the last 12 months from $5.0 \%$ to $5.8 \%(\mathrm{OR}=1.15(0.96-1.39))$. The proportion of adolescents diagnosed with asthma increased from $14.4 \%$ to $16.6 \%(\mathrm{OR}=1.18(1.05-1.33)$ ). However, of those with current asthma, only 284 (33.5\%) had been diagnosed with asthma, and of those with severe asthma, only 223 (33.5\%) had been diagnosed.

\section{Prevalence of symptoms of asthma by video questionnaire}

The video questionnaire was completed by 3944 (99.1\%). Results showed a consistent increase in the prevalence of all measures of asthma and of severe asthma in each of the five video scenarios (table 3 ).

\section{Environmental risk factors}

Several risk factors were associated with current or severe asthma outcomes on the written questionnaire. On multivariate analysis, current asthma was associated with female sex, attending a private school, self-reported current smoking, a parent employed or exposure to pets (table 4). Severe asthma (defined as

TABLE 2 Comparison of prevalence of asthma symptoms by written questionnaire among South African adolescents, 2002 (ISAAC III) and 2017 (GAN I)

\begin{tabular}{|c|c|c|c|}
\hline & $\begin{array}{c}2002 \text { (ISAAC III) } \\
n(\%)\end{array}$ & $\begin{array}{c}2017 \text { (GAN I) } \\
n(\%)\end{array}$ & $\begin{array}{r}2002 \text { to } 2017 \\
\text { OR }(95 \% \mathrm{CI})\end{array}$ \\
\hline Subjects $n$ & 5037 & 3979 & \\
\hline Wheeze ever & $1670(33.1)$ & 1373 (34.5) & $1.06(0.97-1.16)$ \\
\hline Wheezing last 12 months & 1025 (20.3) & $847(21.3)$ & $1.06(0.96-1.17)$ \\
\hline $\begin{array}{l}\text { Four or more attacks of wheezing in last } \\
12 \text { months }\end{array}$ & $254(5.0)$ & $230(5.8)$ & $1.15(0.96-1.39)$ \\
\hline $\begin{array}{l}\text { Woken by wheezing one or more nights per } \\
\text { week in last } 12 \text { months }\end{array}$ & $252(5.0)$ & 275 (6.9) & $1.41(1.18-1.68)$ \\
\hline $\begin{array}{l}\text { Severe wheeze limiting speech to one or two } \\
\text { words at a time in last } 12 \text { months }\end{array}$ & $395(7.8)$ & 468 (11.8) & $1.57(1.36-1.80)$ \\
\hline Exercise-induced wheeze in last 12 months & $1641(32.6)$ & $1431(36.0)$ & $1.16(1.06-1.27)$ \\
\hline Night cough in last 12 months & $1846(36.6)$ & $1648(41.4)$ & $1.22(1.12-1.33)$ \\
\hline Diagnosis of asthma ever & $725(14.4)$ & $660(16.6)$ & $1.18(1.05-1.33)$ \\
\hline
\end{tabular}




\begin{tabular}{|c|c|c|c|}
\hline Timeframe & $\begin{array}{c}2002 \text { (ISAAC III) } \\
n(\%)\end{array}$ & $\begin{array}{c}2017 \text { (GAN I) } \\
n(\%)\end{array}$ & $\begin{array}{l}2002 \text { to } 2017 \\
\text { OR (95\% CI) }\end{array}$ \\
\hline \multicolumn{4}{|l|}{ Wheeze } \\
\hline Ever & 840 (16.9) & $887(22.5)$ & $1.45(1.30-1.61)$ \\
\hline In the last 12 months & 559 (11.2) & $737(18.7)$ & $1.84(1.63-2.07)$ \\
\hline In the last month & $351(7.0)$ & $513(13.0)$ & $1.92(1.66-2.21)$ \\
\hline \multicolumn{4}{|l|}{ Exercise-induced wheeze } \\
\hline Ever & 1070 (21.3) & 1480 (37.5) & $2.23(2.03-2.44)$ \\
\hline In the last 12 months & $692(13.9)$ & $1205(30.6)$ & $2.76(2.49-3.07)$ \\
\hline In the last month & $466(9.4)$ & $890(22.6)$ & $2.86(2.53-3.23)$ \\
\hline \multicolumn{4}{|l|}{ Nocturnal wheeze } \\
\hline Ever & 459 (9.2) & $517(13.1)$ & $1.50(1.32-1.72)$ \\
\hline In the last 12 months & $265(5.3)$ & $376(9.5)$ & $1.90(1.61-2.23)$ \\
\hline In the last month & $194(3.9)$ & $275(7.0)$ & $1.87(1.55-2.26)$ \\
\hline \multicolumn{4}{|l|}{ Nocturnal cough } \\
\hline Ever & $1501(30.1)$ & $1147(29.1)$ & $0.97(0.88-1.06)$ \\
\hline In the last 12 months & $957(19.2)$ & $863(21.9)$ & $1.19(1.08-1.32)$ \\
\hline In the last month & $620(12.5)$ & $618(15.7)$ & $1.32(1.17-1.49)$ \\
\hline \multicolumn{4}{|l|}{ Severe wheeze } \\
\hline Ever & $603(12.1)$ & 583 (14.8) & $1.28(1.13-1.44)$ \\
\hline In the last 12 months & $347(7.0)$ & $403(10.2)$ & $1.47(1.27-1.71)$ \\
\hline In the last month & $216(4.3)$ & $296(7.5)$ & $1.81(1.51-2.17)$ \\
\hline
\end{tabular}

any of the three measures on the written questionnaire) was associated with self-reported smoking $(\mathrm{OR}=2.29$ (1.78-2.94)), living in an informal home $(\mathrm{OR}=1.38$ (1.05-1.81)), exposure to outdoor pollution $(\mathrm{OR}=1.26(1.05-1.51))$ or exposure to pets $(\mathrm{OR}=1.32(1.09-1.61))$ (table 5).

\section{Discussion}

This study is amongst the first globally to use the GAN methodology to investigate changes in asthma prevalence in adolescents in a LMIC over an extended period. A key finding was the increasing prevalence of severe asthma. While asthma prevalence did not change substantially over this period on the written questionnaire, all measures of symptoms of severity increased on the written and video questionnaires. The proportion of children diagnosed with asthma increased, but only a third of those with current or severe symptoms had been diagnosed with asthma. Key environmental exposures associated with asthma or with severe disease were outdoor pollution, participant smoking, pets and poor housing.

The rising prevalence and severity of asthma from 1995 to 2002 has previously been reported amongst adolescents from the same area [9]. These trends were consistent with ISAAC data from other African countries, such as Kenya and Nigeria, which showed an increasing prevalence of asthma compared to a stabilising or decreasing trend in some higher-income countries [5]. In addition, bronchial hyper-responsiveness studies have shown comparable increases in asthma prevalence amongst rural and urban South African children from 1979 and through to 2020 [17-21]. The current study extends these findings by showing a striking increase in disease severity across all measures.

Several factors may account for the greater severity of asthma. Poor living conditions was a key risk factor, as was self-reported smoking, pet ownership and outdoor pollution. Consistent with ISAAC III data from Cape Town, children from higher SES backgrounds (as measured by parental employment or private schooling) had a higher risk of current asthma; however, asthma severity was higher amongst those from a lower SES [22]. In another South African study using self-reported questionnaires amongst 6002 children from both rural and urban settings to investigate socioeconomic risk factors for childhood asthma, asthma severity increased with socioeconomic deprivation [23]. This association may be attributable to both the inequitable distribution of health care, poor access to diagnosis and care and environmental factors, such as increased exposure to indoor pollution and smoking [22, 23].

Self-reported smoking was an important risk factor, with almost $9 \%$ of participants self-reporting smoking at a relatively young age. While self-reported smoking is an imperfect measure, this probably represents the lowest estimate of adolescents who are currently smoking in this population. Exposure to tobacco smoke is a well-established risk factor for asthma [10, 24, 25]. Amongst 6-7-year-old children from a different part of South Africa, exposure to tobacco smoke increased the likelihood of wheeze by $77 \%$ [10]. 
TABLE 4 Univariate and multivariate analysis of exposures and current self-reported asthma on the written questionnaire

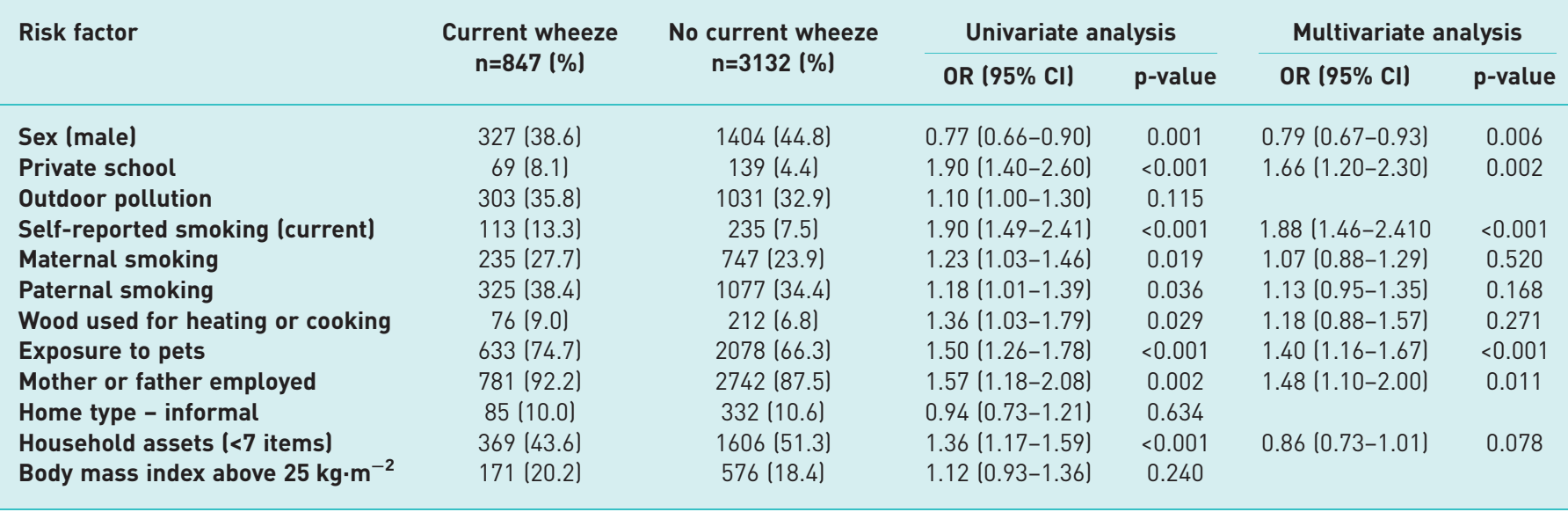

South Africa's Tobacco Products Control Amendment Act (2008) prohibits children younger than 18 years from smoking, regulates the advertisement of cigarettes and cigarette tax, and makes designated smoking areas a legal requirement [26]. Our data suggest the need for more effective enforcement of this legislature as well as improved educational programmes aimed at children and adolescents, to prevent initiation of smoking and to strengthen smoking cessation initiatives for school-going children.

Outdoor pollution, as measured by frequency of trucks passing by the respondent's home, was associated with an increased risk of severe asthma. Outdoor pollution is a well-established risk factor for current and severe asthma [27]. However, data from Sub-Saharan Africa on the strength of the association are limited, with only a few recent studies describing an association between air pollution and wheeze in this region $[27,28]$. With increasing industrialisation, levels of pollution are expected to continue to rise, particularly in urban areas [27]. Further research is therefore needed to accurately describe this relationship in LMICs such as South Africa, and to promote strategies to reduce exposure.

Consistent with ISAAC and other global data, female sex was found to be a significant risk factor for current wheeze amongst adolescents $[4,29,30]$. In pre-pubertal children the prevalence and severity of asthma is higher amongst males. The switch in asthma prevalence at the onset of puberty may be related to the effects of female sex hormones on airway inflammation and hyper-reactivity. Other factors thought to contribute to the gender differences in asthma prevalence include differences in airway growth and function between sexes, a tendency for girls to over-report asthma symptoms, as well as differences in environmental exposures, such as smoking [29, 30].

Lack of asthma diagnosis for adolescents with asthma or with severe disease was common, with two-thirds of cases undiagnosed. This proportion has remained relatively unchanged over this period; in ISAAC III,

TABLE 5 Univariate and multivariate analysis of exposures and severe asthma on the written questionnaire

\begin{tabular}{|c|c|c|c|c|c|c|}
\hline \multirow[t]{2}{*}{ Risk factor } & \multirow{2}{*}{$\begin{array}{c}\text { Severe wheeze } \\
n=669(\%)\end{array}$} & \multirow{2}{*}{$\begin{array}{c}\text { No severe wheeze } \\
n=3310(\%)\end{array}$} & \multicolumn{2}{|c|}{ Univariate analysis } & \multicolumn{2}{|c|}{ Multivariate analysis } \\
\hline & & & OR $(95 \% \mathrm{CI})$ & p-value & OR $(95 \% \mathrm{CI})$ & p-value \\
\hline Sex (male) & $287(42.9)$ & $1444(43.6)$ & $0.97(0.82-1.15)$ & 0.730 & & \\
\hline Outdoor pollution & $260(38.9)$ & $1074(32.4)$ & $1.33(1.12-1.59)$ & 0.001 & $1.26(1.06-1.51)$ & 0.010 \\
\hline Self-reported smoking (current) & $103(15.4)$ & $245(7.4)$ & $2.28(1.78-2.92)$ & $<0.001$ & $2.29(1.78-2.94)$ & $<0.001$ \\
\hline Maternal smoking & $146(21.8)$ & $836(25.3)$ & $0.84(0.68-1.02)$ & 0.079 & & \\
\hline Exposure to pets & $483(72.2)$ & $2228(67.3)$ & $1.26(1.05-1.52)$ & 0.014 & $1.32(1.09-1.61)$ & 0.005 \\
\hline Mother or father employed & $590(88.2)$ & $2933(88.6)$ & $0.89(0.68-1.17)$ & 0.409 & & \\
\hline Home type - informal & 90 (13.5) & $327(9.9)$ & $1.42(1.10-1.82)$ & 0.006 & $1.38(1.05-1.81)$ & 0.019 \\
\hline Household assets ( $<7$ items) & 363 (54.3) & $1612(48.7)$ & $1.25(1.06-1.48)$ & 0.009 & $1.18(0.99-1.42)$ & 0.072 \\
\hline Body mass index above $25 \mathrm{~kg} \cdot \mathrm{m}^{-2}$ & $130(19.4)$ & $617(18.6)$ & $1.05(0.85-1.30)$ & 0.638 & & \\
\hline
\end{tabular}


undiagnosed asthma was most common in African countries, with $40 \%$ of children undiagnosed [9, 31]. The results from our study suggest that ongoing underdiagnosis and undertreatment of childhood asthma remains a key concern. This may be particularly challenging in LMICs, where access to care may be limited, and illnesses such as lower respiratory infections are more likely to be diagnosed [8]. Adolescents may also deny symptoms and underestimate the severity of disease [30]. Improved access to primary health care for diagnosis and affordable essential asthma medication, including inhaled corticosteroids or short-acting beta agonists, can reduce hospitalisations, mortality and costs $[32,33]$. Our data highlight the need for urgent public healthcare interventions to address underdiagnosis in these settings.

A limitation of the study is the lack of generalisability to rural areas; however, the study is relevant to peri-urban and urbanising landscapes of LMICs $[17,18]$. Further, the study was done in Cape Town, an urban area of South Africa, the same area in which ISAAC phase I and III were done. However, South Africa has experienced profound social and economic changes over this period, with increased urbanisation and increased numbers of people living in informal homes [34-36]. An estimated 53\% of the population resided in urban or peri-urban areas in 1994 compared to 78\% in 2013 [37, 38]. A further limitation is reliance on self-reported symptoms as a proxy for disease, rather than a confirmed diagnosis or lung function testing. Self-report may over- or underdiagnose asthma symptoms [39]. However, the ISAAC self-report methodology has been widely used globally and validated against physician assessments $[14,40]$. Furthermore, the use of identical methodology at all three time points makes a valid comparison over time possible [9].

Although questionnaires have been translated and the study was conducted in the language appropriate for each individual, the translations may be limited in their ability to capture the scope of disease as the interpretation of terms such as "wheezing" and "asthma" may not be specific enough in each language. However, the video questionnaire was used to obviate any language issues. Both the video and the written questionnaires confirmed an increase in severe asthma while the prevalence of asthma, as measured by wheeze in the last 12 months, was remarkably consistent between the two $(21.3 \%$ on the written and $18.7 \%$ on the video questionnaire). Further, these adolescents are all school-going, with a relatively high level of literacy. Lastly, the same questionnaires were used in ISAAC and in GAN, making comparison of responses valid.

The study highlights the emerging undiagnosed and increasing burden of asthma, including severe asthma, which is the commonest non-communicable disease in adolescents in LMICs. The key environmental factors associated with disease and disease severity, including smoking, poor housing and poverty, are amenable to public health interventions. Further study of the determinants of disease and long-term impact is needed in LMIC settings. Strategies to improve asthma diagnosis and management in these settings must be strengthened.

Acknowledgements: We thank all the adolescents who participated; the Heads and Administrators of participating schools; the Western Cape Government Department of Education; the study staff; and Associate Prof. Diane Gray and Prof. Mike Levin of the University of Cape Town for their contributions to the adaptation of the environmental questionnaire. We acknowledge the GAN Global Centre in Auckland, New Zealand for the core materials, guidance and support.

Conflict of interest: C.B. Baard reports grants from the South African Medical Research Council and a grant from the Allergy Society of South Africa during the conduct of the study. Z. Franckling-Smith reports grants from the South African Medical Research Council and a grant from the Allergy Society of South Africa during the conduct of the study. J. Munro reports grants from the South African Medical Research Council and a grant from the Allergy Society of South Africa during the conduct of the study. L. Workman reports grants from the South African Medical Research Council and a grant from the Allergy Society of South Africa during the conduct of the study. H.J. Zar reports grants from the South African Medical Research Council and a grant from the Allergy Society of South Africa during the conduct of the study.

Support statement: Funding was provided by grants to H.J. Zar from the South African Medical Research Council and the Allergy Society of South Africa. Funding information for this article has been deposited with the Crossref Funder Registry.

\section{References}

1 The Global Asthma Report 2018. Auckland, New Zealand, Global Asthma Network, 2018. http:// globalasthmareport.org.

2 Asher I, Pearce N. Global burden of asthma among children. Int J Tuberc Lung Dis 2014; 18: 1269-1278.

3 Global Initiative for Asthma. Global Strategy for Asthma Management and Prevention, 2018. Global Initiative for Asthma, 2018. www.ginasthma.org.

4 Mallol J, Crane J, von Mutius E, et al. The International Study of Asthma and Allergies in Childhood (ISAAC) Phase Three: a global synthesis. Allergol Immunopathol (Madr) 2013; 41: 73-85.

5 Asher M, Montefort S, Björkstén B, et al. Worldwide time trends in the prevalence of symptoms of asthma allergic rhinoconjunctivitis, and eczema in childhood: ISAAC Phases One and Three repeat multicountry cross-sectional surveys. Lancet 2006; 368: 733-743. 
6 Ellwood P, Asher M, Beasley R, et al. The International Study of Asthma and Allergies in Childhood (ISAAC): Phase Three rationale and methods. Int J Tub Lung Dis 2005; 9: 10-16.

7 Cruz Á, Stelmach R, Ponte E. Asthma prevalence and severity in low-resource communities. Curr Opin Allergy Clin Immunol 2017; 17: 188-193.

8 Zar HJ, Levin ME. Challenges in treating paediatric asthma in developing countries. Paediatr Drugs 2012; 14: 353-359.

9 Zar H, Ehrlich R, Workman L, et al. The changing prevalence of asthma, allergic rhinitis and atopic eczema in African adolescents from 1995 to 2002. Pediatr Allergy Immunol 2007; 18: 560-565.

10 Masekela R, Gray CL, Green RJ, et al. The increasing burden of asthma in South African children: a call to action. S Afr Med J 2018; 108: 537-539.

11 Mayosi BM, Lawn JE, van Niekerk A, et al. Health in South Africa: changes and challenges since 2009. Lancet 2012; 380: 2029-2043.

12 Burger R, Christian C. Access to health care in post-apartheid South Africa: availability, affordability and accessibility. Health Econ Policy Law 2018; 15: 43-55.

13 National Planning Commission. Diagnostic overview. 2011. https://www.gov.za/sites/default/files/gcis_document/ 201409/npcdiagnosticoverview1.pdf. Date last accessed: March 3, 2021.

14 Ellwood P, Asher MI, Ellwood E, Global Asthma Network Steering Group. Global Asthma Network Phase I Manual. Global Surveillance: Prevalence, Severity, Management and Risk Factors. 2015. www. globalasthmanetwork.org.

15 Myer L, Stein DJ, Grimsrud A, et al. Social determinants of psychological distress in a nationally-representative sample of South African adults. Soc Sci Med 2008; 66: 1828-1840.

16 City of Cape Town - 2011 Census - Cape Town. 2012. https://resource.capetown.gov.za/documentcentre/ Documents/Maps. Date last accessed: March 3, 2021.

17 Van Niekerk CH, Weinberg EG, Shore SC, et al. Prevalence of asthma: a comparative study of urban and rural Xhosa children. Clin Allergy 1979; 9: 319-324.

18 Steinman HA, Donson H, Kawalski M, et al. Bronchial hyper-responsiveness and atopy in urban, peri-urban and rural South African children. Paediatr Allergy Immunol 2003; 14: 383-393.

19 Calvert J, Burney P. Effect of body mass on exercise-induced bronchospasm and atopy in African children. J Allergy Clin Immunol 2005; 116: 773-779.

20 Levin ME, Muloiwa R, Motala C. Associations between asthma and bronchial hyper-responsiveness with allergy and atopy phenotypes in urban black South African teenagers. S Afr Med J 2011; 101: 472-476.

21 Levin ME, Botha M, Basera W, et al. Environmental factors associated with allergy in urban and rural children from the South African Food Allergy (SAFFA) cohort. J Allergy Clin Immunol 2020; 145: 415-426.

22 Poyser M, Nelson H, Ehrlich R, et al. Socioeconomic deprivation and asthma prevalence and severity in young adolescents. Eur Respir J 2002; 19: 892-898.

23 Yakubovich A, Cluver L, Gie R. Socioeconomic factors associated with asthma prevalence and severity among children living in low-income South African communities. S Afr Med J 2016; 106: 407-412.

24 Stern DA, Morgan WJ, Halonen M, et al. Wheezing and bronchial hyperresponsiveness in early childhood as predictors of newly diagnosed asthma in early adulthood: a longitudinal birth-cohort study. Lancet 2008; 372: $1058-1064$.

25 Ayuk AC, Ramjith J, Zar HJ. Environmental risk factors for asthma in 13-14 year old African children. Pediatr Pulmonol 2018; 53: 1475-1484.

26 Tobacco Products Control Amendment Act, 2008. Government Gazette. www.tobaccosa.co.za/wp-content/ uploads/Amendment-Act-63-of-2008.pdf.

27 Shirinde J, Wichmann J, Voyi K. Association between wheeze and selected air pollution sources in an air pollution priority area in South Africa: a cross-sectional study. Environ Health 2014; 13: 32.

28 Mentz G, Robins T, Batterman S, et al. Acute respiratory symptoms associated with short term fluctuations in ambient pollutants among schoolchildren in Durban, South Africa. Environ Pollut 2018; 233: 529-539.

29 Postma D. Gender differences in asthma development and progression. Gend Med 2007; 4: 133-146.

30 de Benedictis D, Bush A. The challenge of asthma in adolescence. Pediatr Pulmonol 2007; 42: 683-692.

31 Lai CKW, Beasley R, Crane J, et al. Global variation in the prevalence and severity of asthma symptoms: Phase Three of the International Study of Asthma and Allergies in Childhood (ISAAC). Thorax 2009; 64: 476-483.

32 Comaru T, Pitrez PM, Friedrich FO, et al. Free asthma medications reduces hospital admissions in Brazil. Respir Med 2016; 121: 21-25.

33 Soto-Martinez M, Avila L, Soto N, et al. Trends in hospitalizations and mortality from asthma in Costa Rica over a 12- to 15-year period. J Allergy Clin Immunol Pract 2014; 2: 85-90.

34 The World Bank. Urban Poverty: A Global View. Washington, DC, The World Bank, 2008. http://documents1. worldbank.org/curated/en/954511468315832363/pdf/430280NWP0Glob10Box327344B01PUBLIC1.pdf.

35 UN-Habitat. Measurement of City Prosperity: Methodology and Metadata. Nairobi, Kenya, United Nations Human Settlements Programme, 2016.

36 United Nations Conference on Housing and Sustainable Urban Development. Habitat III Issue Papers: Informal Settlements. New York, UN- Habitat, 2015. https:/unhabitat.org/sites/default/files/download-manager-files/ Habitat-III-Issue-Paper-22_Informal-Settlements-2.0 (2). Date last accessed: March 3, 2021.

37 van Huyssteen E, Mans G, le Roux A, et al. CSIR Policy Brief 2: Reaching development outcomes through a dedicated focus on cities, town and settlements. 2013. http://stepsa.org/pdf/policy_implication_notes/CSIR\% 20Policy\%20Brief\%202\%20Reaching\%20development\%20outcomes\%20through\%20a\%20dedicated\%20focus.pdf. Date last accessed: March 3, 2021.

38 Naidoo RN, Robins TG, Batterman S, et al. Ambient pollution and respiratory outcomes among schoolchildren in Durban, South Africa. S Afr J Child Health 2013; 7: 127-134.

39 Romano-Zelekha O, Graif Y, Sultan S, et al. Adolescent versus parent reports on asthma and asthma symptoms. Pediatr Pulmonol 2017; 52: 154-159.

40 Jenkins M, Clarke J, Carlin J, et al. Validation of questionnaire and bronchial hyperresponsiveness against respiratory physician assessment in the diagnosis of asthma. Int J Epidemiol 1996; 25: 609-616. 